
Not for reproduction, distribution or commercial use.

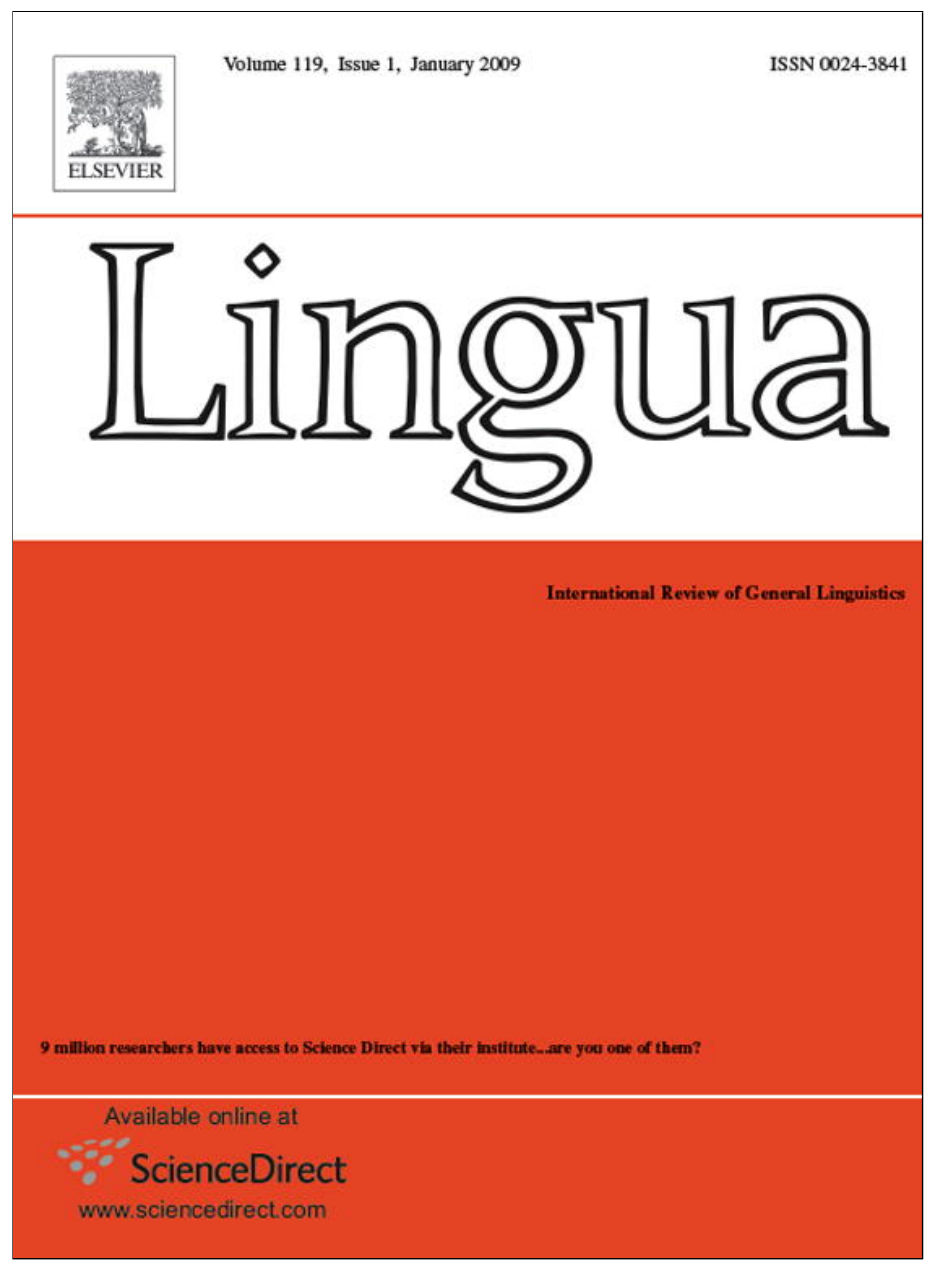

This article appeared in a journal published by Elsevier. The attached copy is furnished to the author for internal non-commercial research and education use, including for instruction at the authors institution and sharing with colleagues.

Other uses, including reproduction and distribution, or selling or licensing copies, or posting to personal, institutional or third party websites are prohibited.

In most cases authors are permitted to post their version of the article (e.g. in Word or Tex form) to their personal website or institutional repository. Authors requiring further information regarding Elsevier's archiving and manuscript policies are encouraged to visit:

http://www.elsevier.com/copyright 


\title{
Relativized relatives: Types of intervention in the acquisition of A-bar dependencies
}

\author{
Naama Friedmann ${ }^{\mathrm{a}, *}$, Adriana Belletti ${ }^{\mathrm{b}}$, Luigi Rizzi ${ }^{\mathrm{b}}$ \\ ${ }^{a}$ Language and Brain Lab, School of Education, Tel Aviv University, Tel Aviv 69978, Israel \\ ${ }^{\mathrm{b}}$ CISCL - Centro Interdipartimentale di Studi Cognitivi sul Linguaggio, Università di Siena, Complesso San Niccolò, Siena, Italy
}

Received 8 August 2008; accepted 1 September 2008

Available online 30 October 2008

\begin{abstract}
Young children find (some) object relatives much harder to understand than subject relatives. The main finding of this article is that not all object relatives are difficult. The difficulty with object relatives (and object Wh-questions) is selective: it depends on the structural similarity between the A'-moved element and the intervening subject. We interpret this selective effect in terms of a proper extension of Relativized Minimality, the principle of syntactic theory which expresses locality effects linked to intervention, and whose psycholinguistic relevance has been highlighted in Grillo's work on agrammatism. Six experiments have been conducted with 22 Hebrew-speaking children aged 3;7-5;0 to substantiate our claims empirically. Experiments 1 and 2 tested the comprehension of headed subject and object relatives with and without a resumptive pronoun, in sentences with lexically restricted (D NP) subjects. Subject relatives were comprehended well, but the performance on object relatives was at chance. The addition of resumptive pronouns did not improve comprehension. Experiments 3 and 4 manipulated the lexical restriction of the moved element and the intervening subject, using free relatives and impersonal pro subjects, respectively. When the moved constituent and the intervening subject were structurally dissimilar in terms of lexical-NP restriction, the performance significantly improved. Experiment 5 showed a similar comprehension pattern in another type of A' movement: Wh-questions. The comprehension of who and which subject and object questions was difficult only when both the crossing element and the intervener included a lexical NP restriction. Finally, a similar pattern emerged in production: in an elicited production study, children showed a tendency to avoid producing structures in which both the moved element and the intervener are lexically restricted. We conclude suggesting a line of analysis of the difference between children and adults in dealing with object A'-dependencies.
\end{abstract}

(C) 2008 Elsevier B.V. All rights reserved.

Keywords: Acquisition; Relative clauses; Hebrew; Syntax; Relativized minimality

\section{Introduction}

This paper deals primarily with the fact that object relatives are not properly processed by young children, whereas subject relatives are (a classical observation from the literature; see Adams, 1990; Berman, 1997; Brown, 1972; Correa, 1982, 1995; de Villiers et al., 1994; McKee et al., 1998; Roth, 1984; Sheldon, 1974; Tavakolian, 1981). Subject and object relatives differ with respect to the position from which movement takes place. As seen in (1), in subject

\footnotetext{
* Corresponding author. Tel.: +972 36405257.

E-mail address: naamafr@post.tau.ac.il (N. Friedmann).
} 
relatives the movement is from embedded subject position, and in object relatives the movement is from the object position. The original position is marked by an underline.

Subject relative: The boy that hugs the monkey

Object relative: The boy that the monkey hugs

This asymmetry between the two kinds of relatives in development has a counterpart in adult performance: both kinds are grammatical, and accessible to the adult parser, but parsing of object relatives is harder than that of subject relatives - a line of studies since the seventies showed that they take more time and are more prone to errors (Cook, 1975; Ford, 1983; Frauenfelder et al., 1980; Hakes et al., 1976). Processing studies in English suggest that the parser tries to close an A' dependency as soon as possible: when an A' binder is processed, the parser tries to postulate the variable in the closest argument position, the subject position (so called "active filler" effect; Crain and Fodor, 1985; Frazier and Clifton, 1989; Frazier and Flores d'Arcais, 1989; Frazier et al., 1983; Stowe, 1986). Such a resourcesaving strategy (clearly expressed, e.g., by De Vincenzi's, 1991 Minimal Chain Principle) succeeds with subject relatives but fails with object relatives, which require reanalysis; whence the accrued complexity of object relatives.

It appears natural to restate the effect in terms of intervention: the A' dependency fails (in young children) and is harder (in adults) when the terms to be connected in the dependency are separated by an intervener, a position which could potentially be involved in the A' relation: typically the subject position, which would be a potential site for the variable. Once stated in terms of intervention, the effect becomes strongly reminiscent of major intervention effects that syntactic theory has uncovered. Consider the non-extractability of certain Wh elements from an indirect question, exemplified in (2):

(2) *How do you wonder who behaved ?

This is a familiar relativized minimality effect (Rizzi, 1990): how cannot be related to its trace, the position where it is originally merged, because of the intervention of the Wh operator who in the embedded complementizer system. More precisely, relativized minimality (RM) states that in the configuration (3), a local relation cannot hold between $X$ and $\mathrm{Y}$ when $\mathrm{Z}$ intervenes, and $\mathrm{Z}$ is somehow a potential candidate for the local relation.

$$
X \ldots Z \ldots Y
$$

The structural analogy between RM configurations and intervention effects making certain structures unparsable or anyhow problematic has been proposed in recent work by Grillo $(2005,2008)$ on individuals with agrammatism. ${ }^{1} \mathrm{We}$ want to explore and structure an approach along similar lines for the developmental effects with regard to A' dependencies.

Various questions are raised by this line of inquiry:

1. Is there just a vague analogy between the difficulty children experience with object relatives and certain extraction impossibilities such as (2)? Or the same precise formal principle, RM, can be assumed to be operative in both cases?

2. If RM is indeed operative, why does it seemingly behave in a stricter fashion in children than it does in adults, whose grammar and parsing system clearly can cope with object relatives? Of course object relatives are grammatical and routinely permitted in adult performance, even though complexity effects emerge also at this stage.

3. What changes in development that allows children to come to understand these structures?

4. How does the early incapacity to properly deal with object relatives relate to the complexity effect in adult parsing?

We want to argue for the hypothesis that a single formal principle is operative in all these cases: if complemented with auxiliary hypotheses, the same principle can underlie both grammaticality judgments and performance effects in adults as well as graded difficulties in children. In this paper we will focus on children's performance, combining experimental results on Hebrew-speaking children and insights gained from theoretical work on linguistic locality.

\footnotetext{
${ }^{1}$ Some accounts for the difficulty in certain wh-movement structures in impaired populations also used the notion of crossing of another (similar) argument, without reference to RM effect. For agrammatic aphasia, see Friedmann and Shapiro (2003), Friedmann (2008) and Grodzinsky (2006). For syntactic SLI see Friedmann and Novogrodsky (in press).
} 
We will start by illustrating the basic effect of the difference in comprehension between subject and object relatives in young children, and then report additional experiments in which the properties of the intervener or of the A' binder are manipulated.

\section{Experiments 1-4: testing the comprehension of relative clauses}

Experiments 1-4 tested the comprehension of various types of subject and object relative clauses in Hebrewspeaking kindergarten children.

\subsection{General method}

\subsubsection{Participants}

The participants in Experiments 1-4 were 22 children aged 3;7-5;0 $(M=4 ; 6$, S.D. $=0 ; 5)$ from two Israeli kindergartens, all native speakers of Hebrew. The group consisted of 8 girls and 14 boys with no diagnosed language, hearing, or speech pathologies, from families of middle-high SES.

\subsubsection{Materials and design}

Relative clause comprehension was tested in one of two ways, a sentence-picture matching task or a sentencescenario matching task. The testing method was manipulated between participants: The children were divided into two groups matched for age, and each group was tested for relative clause comprehension using one of the two tasks.

In both methods, participants were orally presented with a relative clause. In the sentence-picture matching task, two pictures from BAMBI (Friedmann and Novogrodsky, 2002) were presented: One of the pictures matched the sentence, and in the other picture the two arguments were reversed (see Fig. 1).
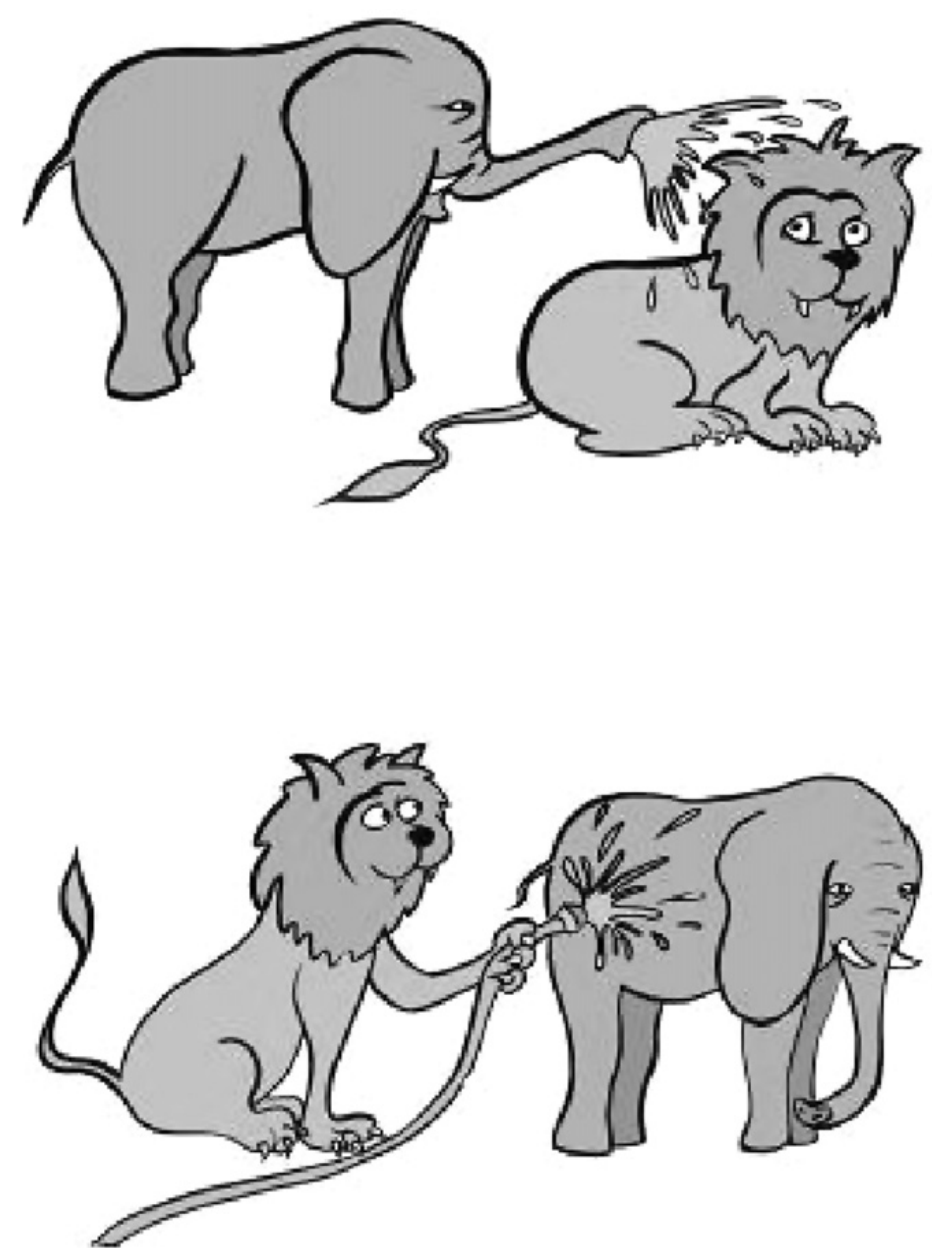

Fig. 1. A picture used in sentence-picture matching task. 


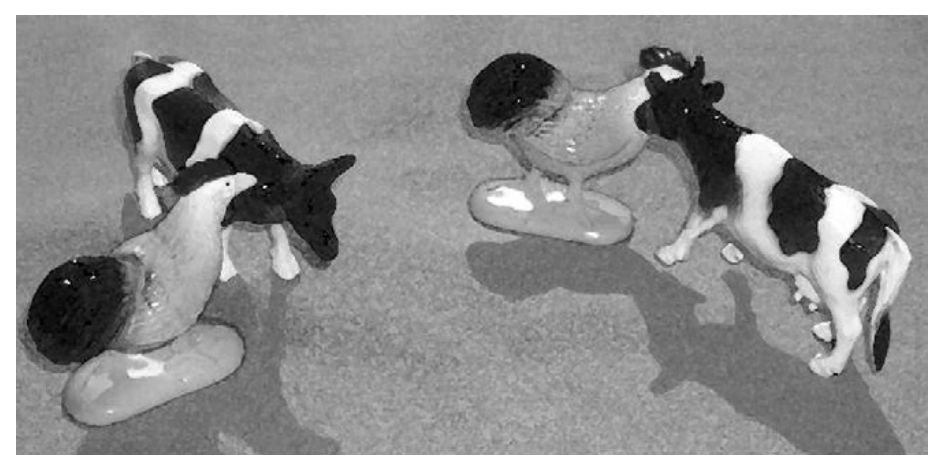

Fig. 2. A scenario acted out in the sentence-scenario matching task.

In the sentence-scenario matching task, two scenarios were presented by the experimenter, one of which matched the sentence and the other involved a reversal of the two arguments (as shown in Fig. 2). The children were asked to point at the picture or at the scenario that matched the sentence.

In the four experiments a total of 84 sentences were presented to the children, 14 of each type. In each sentence the figures were always of the same gender and number, for example, a grandmother and a girl; an elephant (masculine) and a lion (masculine), etc. This was done to keep the noun phrases as similar as possible and to preclude an agreement cue on the verb (which, in Hebrew, agrees with the subject in gender, number, and person).

In the task that tested sentence comprehension using pictures, 28 pictures were presented, each picture was presented 3 times with 3 different relative clause types (see Appendix A for a list of the pictures). The six sentence types in the four experiments were presented in a randomized order, so that the same sentence type did not appear in more than two consecutive items. Additionally, the target picture did not appear in the same location on the page (up/ down) for more than two consecutive sentences. There was no correlation between sentence type and picture position.

In the task that tested sentence comprehension using scenarios, two scenarios were displayed simultaneously, with two identical pairs of animals performing the same action with reversed roles. For example, in Fig. 2, chicken A is kissing cow A, and cow B is kissing chicken B. The two pairs of animals remained in their respective positions while the sentences pertaining to those scenarios were presented one after the other (see Appendix A for a list of the scenarios). The six sentence types were presented in a randomized order, with each of the scenarios. Seven pairs of scenarios were presented to each child.

There was no time limit. During the test, every several items, the participants were given colorful stickers to stick on a separate piece of paper, to maintain their interest in performing the task. The test was administered in two sessions.

\subsection{Experiment 1: The comprehension of subject and object headed relative clauses}

Experiment 1 compared the comprehension of subject and object headed relative clauses.

\subsubsection{Materials}

The sentences were 28 headed relative clauses: 14 headed subject relatives (see example 4), and 14 headed object relatives (example 5). For all relative clauses we used clauses with two referential noun phrases, both kinds of relatives contained a gap in the merge position.

$$
\begin{aligned}
& \text { Tare li et ha-para she-menasheket et ha-tarnegolet. } \\
& \text { show to-me ACC the-cow that-kisses ACC the-chicken } \\
& \text { 'Show me the cow that is kissing the chicken.' } \\
& \text { Tare li et ha-pil she-ha-arie martiv. } \\
& \text { show to-me ACC the-elephant that-the-lion wets } \\
& \text { 'Show me the elephant that the lion is wetting.' }
\end{aligned}
$$

\subsubsection{Results}

The data presented in Table 1 indicate that the children we tested already understand subject relatives. The grouplevel performance was above chance, regardless of the testing method (pictures or scenarios). On the individual level 
Table 1

Percentage of correct responses and number of participants who performed above chance

\begin{tabular}{lll}
\hline & Headed subject relative & Headed object relative \\
\hline Pictures & $92 \%$ & $70 \%$ \\
Scenarios & $89 \%$ & $38 \%$ \\
Combined & $90 \%$ & $55 \%$ \\
No. of participants of 22 who performed above chance & 22 & 7 \\
Group-level above chance & Yes & No \\
\hline
\end{tabular}

too, each child performed above chance on subject relatives. However, this was not the case in object relatives. The participants showed poor performance with object relatives. The group of participants performed at chance level, and only 7 of the 22 participants performed above chance with object relatives (none in the scenario task). The difference between subject and object relatives is sharper in the Scenario task than in the Picture task; it seems that the use of the scenarios magnifies the difficulty of the difficult structures, i.e., object relatives, and hence increases the difference between the comprehension of subject- and object relatives; without trying to develop a thorough explanation as to why it should be so, we just note that in the practice of administering the two tests, children had more interest in playing with the puppets in the scenarios: interestingly, however, this led them to give up the task only when they heard object relatives, and not with subject relatives, giving another type of support for the difference between the comprehension of the two kinds of relatives. The better performance in the Picture than in the Scenario task has been consistent across different structures to be presented in the following experiments as well. Crucially, subject relatives were comprehended significantly better than object relatives consistently in both the picture and the scenario tasks, and in the combined analysis, $t(21)=7.18, p<.001$.

An additional experiment, with 31 Hebrew-speaking children in the same age range $(3 ; 7-5 ; 5, M=4 ; 7)$, which used the picture task (Günzberg-Kerbel et al., 2008), yielded very similar results, of $85 \%$ correct in the subject relatives, and $67 \%$ correct in object relatives. Taking the 53 children together, again, subject relatives were comprehended significantly better than object relatives, $t(52)=9.06, p<.001$.

This difficulty with object relatives is overcome at around the age of 6 (Friedmann and Novogrodsky, 2004).

\subsubsection{Interim discussion 1}

These results from Hebrew are consistent with previous findings in other languages (Adams, 1990; Berman, 1997; Correa, 1995; de Villiers et al., 1994; Håkansson and Hansson, 2000; McKee et al., 1998; Roth, 1984; Sheldon, 1974; Tavakolian, 1981), indicating a better performance in children of this age range on subject than object relatives. All the participants performed above chance with subject relatives, but only one third did so with object relatives. Why should it be so? A plausible reason could be that the two elements involved in the Wh dependency are somehow structurally farther apart in the case of object relatives than in subject relatives. More specifically, the presence of an intervening constituent in the object relatives could be the relevant factor. Whereas in object relatives the overt embedded subject intervenes between the relative head and the gap in the original merge position, no such intervener is present in subject relatives. The schema in (6) illustrates the two structures (where R designates the relative complementizer, and D NP designates a nominal expression introduced by a determiner). ${ }^{2}$ In a subject relative (6)a there is no intervener between the gap (__ relative head, so it is comprehended well by children (denoted by "ok"). In object relatives, however, the dependency crosses over another D NP in subject position, causing comprehension problems in object relatives (denoted by *).

a. Headed subject relative

$$
\begin{aligned}
& \text {... the cow that } \\
& \text { kisses the chicken } \\
& \ldots \mathrm{D} \text { NP R ... ... D NP ok }
\end{aligned}
$$

b. Headed object relative

... the chicken that the cow kisses

$$
\text { ... D NP R ... D NP .. }
$$

\footnotetext{
${ }^{2}$ We adopt here the DP hypothesis (Abney, 1987) according to which nominal arguments are introduced by the functional element $\mathrm{D}$ giving rise to its own projection, the DP, and taking as complement the NP, the projection of the lexical N.

We assume a raising analysis of relative clauses as in Vergnaud (1974), Kayne (1994), and Bianchi (1999); the raising analysis allows us to make our general point more perspicuous, but our proposal is also consistent with at least some versions of the matching analysis.
} 
This contrast has a "minimal distance" flavor which is reminiscent of a relativized minimality (RM) effect. The basic configuration illustrating the application of RM is reproduced in (7).

$$
\mathrm{X} \ldots \mathrm{Z} \ldots \mathrm{Y}
$$

For the sake of clarity, given the skeleton in (7), we call X the "target" of the local relation (typically the landing site of movement, or the antecedent in other types of A' dependencies), Z the "intervener", and Y the "origin". A local relation between the target $\mathrm{X}$ and the origin $\mathrm{Y}$ fails if an element $\mathrm{Z}$ intervenes which is similar in internal constitution to X. Postponing to the general Discussion section a precise formal definition of "similarity", we keep the presentation at an intuitive level here and propose that the D NP shape shared by the relative head and the intervening subject in (6)b, i.e., the fact that both contain a lexical restriction, is sufficient to trigger the intervention effect in children, making the object relative configuration problematic.

This hypothesis makes immediate predictions: if we manipulate the structural constitution of the elements involved, thus making $\mathrm{X}$ and $\mathrm{Z}$ sufficiently different, we should expect a facilitating effect in the understanding of the structure. Experiments 3 and 4 address precisely this question. Experiment 3 manipulates the internal constitution of the target by investigating the comprehension of free relatives; Experiment 4 manipulates the shape of the intervener by using sentences with a null pronominal arbitrary subject. But first of all we verify the existence of intervention effects with the other major strategy for relative clause formation in Modern Hebrew, which involves a resumptive pronoun. This is investigated in Experiment 2.

\subsection{Experiment 2: Comprehension of headed object relatives with a resumptive pronoun}

In Experiment 2 we tested the way the same children comprehend object relatives with a resumptive pronoun. Resumptive pronouns in Hebrew are optional with the type of object relatives used in the current study. Given the raising analysis that we have been assuming for relative clauses, a resumptive structure is directly obtained through a doubling + stranding derivation of the resumptive relatives, with the origin containing both the pronoun and the relative head in a "big DP" (Belletti, 2005, 2006; Boeckx, 2003). The relative head is raised and the pronoun is stranded within the relative clause. Should one adopt a "base-generation analysis" of resumptive relatives, as has been often assumed, the target containing the lexical NP restriction would be generated in the relative head position. In this case, the origin would be an independently merged pronoun related to the target through some interpretive mechanism. Although we do not want to take a definite stand here on which analysis should be considered the most adequate one for resumptive object relatives in general, for concreteness we will assume the raising doubling + stranding analysis which, all other things being equal, minimizes the difference with the gap relatives.

\subsubsection{Method}

The test included 14 object relatives with a resumptive pronoun (example 8 ).

(8) Tare li et ha-kof she-ha-yeled mexabek oto.

show to-me ACC the-monkey that-the-boy hugs him

'Show me the monkey that the boy is hugging.'

\subsubsection{Results}

The comprehension of object relatives with a resumptive pronoun is presented in Table 2 (in shaded columns), in comparison to the results already obtained in Experiment 1 for object relatives with a gap. These results clearly indicate that headed object relatives with a resumptive pronoun are also problematic for children, as only 6 of the 22 children performed above chance in this structure, and the group did not perform significantly above chance. The results also indicate that this difficulty is similar to the children's difficulty with headed object relative clauses with a gap, with no significant difference between object relatives with and without a resumptive pronoun, $t(21)=0.39, p=.70$.

Again, an analysis combined with the additional 31 children reported by Günzberg-Kerbel et al. (2008) yields no difference between object relatives with and without a resumptive pronoun, in all 53 children combined, $t(52)=0.09$, $p=.93$. 
Table 2

Percentage of correct responses and number of participants who performed above chance for object relatives with a resumptive pronoun, compared to other types of headed relative clauses

\begin{tabular}{lccc}
\hline & Headed & Headed & Resumptive \\
& subject relative & object relative & object relative \\
\hline Pictures & $92 \%$ & $70 \%$ & $61 \%$ \\
Scenarios & $89 \%$ & $38 \%$ & $50 \%$ \\
Combined & $90 \%$ & $55 \%$ & $56 \%$ \\
No. of participants of 22 who & & & \\
performed above chance & 22 & 7 & No \\
Group-level above chance? & Yes & & \\
\hline
\end{tabular}

\subsubsection{Interim discussion 2}

The main result of Experiment 2 is that the same difficulty found in the comprehension of headed object relatives with a gap in the merge position of the argument is maintained also when a resumptive pronoun is present in the merge position of the object relative DP. Given our line of interpretation of the detected asymmetries in comprehension, this result does not come as a surprise since the target and the intervener contain a lexical NP restriction in both cases. Given the raising doubling + stranding analysis of resumptive headed object relatives, it is expected that the comprehension of headed object relatives with a resumptive pronoun should not differ from the comprehension of headed object relatives with a gap. Under this analysis, resumptive and non-resumptive relatives differ only in a minimal fashion, in that movement is the common dependency-creating operation and a trace is involved in both cases, except that the trace is overtly signaled by the stranded pronoun in the resumptive relative. We therefore expect that an intervening lexically restricted DP will interfere in the dependency between the lexically restricted head and its trace in both cases.

Similar considerations hold if one were to assume a non-movement analysis of object relatives with a resumptive pronoun, in which no big DP is involved and the pronoun is independently merged in argument position. In this case, one should conclude that the relevant intervention principle applies also to other types of A'-dependencies, not involving movement.

\subsection{Experiment 3: The comprehension of free relatives}

Experiment 3 tested the comprehension of subject- and object relatives which minimally differ from the ones used in Experiment 1 in that the moved element is a pure Wh operator, an operator which does not contain a lexical NP restriction. Thus, in this object relative structure the lexical subject intervener and the target are different in nature, in that a lexical NP restriction is specified in the intervener, but not in the target. This configuration was obtained via the use of free relatives. Free relatives in Hebrew (examples 9, 10) are constructed with a relative operator that corresponds to the Wh element (such as $m i$, who, or $m a$, what), and a complementizer, she- (Grosu, 2003). The use of the construction is quite widespread in Hebrew to express a relative with no lexical restriction (corresponding to English "the one that...", Italian "quello che...", etc.). The comprehension of these sentences was tested for the same children who participated in Experiments 1 and 2.

\subsubsection{Material}

The test included 28 sentences, 14 free subject relatives (example 9), and 14 free object relatives (example 10).

(9) Tare li et mi she-martiv et ha-yeled. show to-me ACC who that-wets ACC the-boy 'Show me the one that is wetting the boy.' 
Table 3

Percentage of correct responses and number of participants who performed above chance for free and headed relative clauses

\begin{tabular}{|c|c|c|c|c|c|}
\hline & $\begin{array}{l}\text { Headed } \\
\text { subject } \\
\text { relative }\end{array}$ & $\begin{array}{c}\text { Headed } \\
\text { object } \\
\text { relative }\end{array}$ & $\begin{array}{c}\text { resumptive } \\
\text { object } \\
\text { relative }\end{array}$ & $\begin{array}{c}\text { Free } \\
\text { subject } \\
\text { relative }\end{array}$ & $\begin{array}{l}\text { Free } \\
\text { object } \\
\text { relative }\end{array}$ \\
\hline Pictures & $92 \%$ & $70 \%$ & $61 \%$ & $85 \%$ & $87 \%$ \\
\hline Scenarios & $89 \%$ & $38 \%$ & $50 \%$ & $83 \%$ & $70 \%$ \\
\hline Combined & $90 \%$ & $55 \%$ & $56 \%$ & $84 \%$ & $79 \%$ \\
\hline \multicolumn{6}{|l|}{ No. of participants of 22 who } \\
\hline performed above chance & 22 & 7 & 6 & 18 & 17 \\
\hline Group-level above chance & Yes & No & No & Yes & Yes \\
\hline
\end{tabular}

Tare li et mi she-ha-yeled menadned.

show to-me ACC who that-the-boy swings

'Show me the one that the boy is wetting.'

\subsubsection{Results}

The results of Experiment 3 were that both free subject relatives and free object relatives were comprehended well. Table 3 presents, in addition to the results of the current experiment (in shaded columns), also the scores of the same 22 children on headed relative clauses in Experiments 1 and 2. These results indicated that the performance on the free object relatives was significantly better than on the headed object relatives, both in the picture task and in the scenarios $(t(21)=4.21, p<.001$ combined $)$.

The subject relatives were already comprehended well with a full noun phrase as a head, so the comprehension of free subject relatives was only marginally significantly better than headed subject relatives, $t(21)=2.07, p=.05$.

The group-level performance on the free subject- and, crucially, also on the free object relatives was above chance, regardless of the testing method (pictures or scenarios). On the individual level, 18 and 17 of the 22 children performed above chance on free subject relatives and free object relatives, respectively, clearly better than the number of participants who performed above chance on headed object relatives, which was less than a third of the participants.

\subsubsection{Interim discussion 3}

On the basis of these results, it can be concluded that the sweeping statement that, for children of the relevant age range, object relatives are difficult to comprehend is too coarse, as it only applies to specific types of object relatives: headed object relatives are indeed more difficult to comprehend than headed (or free) subject relatives. However, free object relatives are much easier to comprehend than headed object relatives, and about on a par with subject relatives.

Let us make somewhat more explicit the analytical assumptions adopted so that the relevant distinction between the cases of headed and free relative clauses can emerge more clearly. We continue to assume a raising analysis of relative clauses. According to this analysis, the relative head raises to the left peripheral position within $\mathrm{CP}$ from the argument position in which it is merged within the relative clause. We assume that the presence of a lexical NP restriction, by which we mean a lexical overt noun phrase within the DP, is the crucial factor. This lexical NP restriction within the relative head determines the intervention effect in headed relative clauses. When the subject also contains a lexical NP restriction, it interferes in the connection between the relative head and its trace, as in (6)b, repeated below as (11)a. If this is how RM can be applied in the case of the results of Experiment 1, the fact that the relative operator in free relatives does not contain any lexical NP restriction should disqualify the subject as an intervener in the technical sense defined for (7); thus, although it is structurally located between the two positions to be locally related, the target and the origin, it does not provoke any blocking effect. This is schematized in (11)b, compared here with the headed relative structure (11)a. 
(11) a. Headed object relative

... the chicken that the cow kisses

... D NP R ... D NP ...

b. Free object relative

...who that-the-boy swings

...Wh R ... D NP ...

ok

Experiment 3 thus shows that when the crossing element does not include a lexical NP restriction, a full subject noun phrase does not create an intervention effect. We should now ask what happens in the complementary case, i.e., when the moved element has a lexical NP restriction, but it crosses a subject that has no lexical NP restriction. Under a RM approach to the difficulty in relative clause comprehension, these structures too are expected to be easier to understand. Experiment 4 tested this prediction using a null impersonal pro with arbitrary interpretation in embedded subject position.

\subsection{Experiment 4: The comprehension of headed object relatives with an impersonal arbitrary pro subject}

Experiment 4 tested the comprehension of object relatives in which the moved element is a full noun phrase with a lexical NP restriction, but the possible intervener does not have any lexical NP restriction. Thus, the intervener and the crossing element are again of different types. This was done via the use of an impersonal pro subject with an arbitrary interpretation. Hebrew uses an arbitrary pro that has plural specifications (shown on the agreeing verb; Shlonsky, 1997), and which indicates that someone is performing the action, not necessarily a plural agent.

\subsubsection{Material}

The test included 14 object relatives with an arbitrary pro embedded subject (example 12). We used here resumptive relatives because they sound much more natural than gap relatives in co-occurrence with an arbitrary subject, for reasons which will not be investigated here. As shown in Experiment 2, the use of a resumptive pronoun does not improve comprehension anyway.
Tare li et ha-sus she-mesarkim oto. show to-me ACC the-horse that-brush-pl him 'Show me the horse that someone is brushing.'

\subsubsection{Results}

The results, presented in Table 4 (in the shaded column) with previous results of the same 22 children on relative clauses for comparison, indicate again that object relatives can be understood well when the intervener is not of the same type as the crossing element, in terms of lexical NP restriction. The object relatives with the arbitrary pro were comprehended significantly better than the headed object relatives, $t(21)=5.93, p<.0001$. The measure of the number of children who performed above chance also indicates that this structure was much easier for them than the headed object relative: 19 children performed above chance on the object relatives with an arbitrary pro subject, compared to only 7 for headed object relatives.

\subsection{Analyses across the six relative clause types}

A different type of analysis gives rise to another important finding concerning the sequence of acquisition of the various types of relative clauses. The combined results of Experiments 1, 3, and 4 indicate that out of the five constructions tested, the first to be acquired is the headed subject relative clause. All of the children performed above chance on this type of sentence - hence, any child that performed above chance on any other type of relative clause performed above chance on headed subject relatives as well. Additionally, the acquisition of free object relatives and object relatives with an impersonal pro subject always precedes the acquisition of headed object relatives with a gap. That is to say, any child who performed above chance on headed object relatives also performed above chance on free object relatives and on object relatives with an impersonal pro subject. ${ }^{3}$

\footnotetext{
${ }^{3}$ If use a stricter criterion for mastery, of two-tailed rather than one-tailed comparisons (significantly different from chance, 11 out of 14 instead of significantly above chance, 10 of 14), this pattern remains and headed object relatives with a resumptive pronoun become the last structure to be acquired.
} 
Table 4

Percentage of correct responses and number of participants who performed above chance for object relatives with an arbitrary pro embedded subject, compared to free and headed relative clauses

\begin{tabular}{|c|c|c|c|c|c|c|}
\hline & $\begin{array}{l}\text { Headed } \\
\text { subject } \\
\text { relative }\end{array}$ & $\begin{array}{l}\text { Headed } \\
\text { object } \\
\text { relative }\end{array}$ & $\begin{array}{c}\text { Resumptive } \\
\text { object } \\
\text { relative }\end{array}$ & $\begin{array}{c}\text { Free } \\
\text { subject } \\
\text { relative }\end{array}$ & $\begin{array}{l}\text { Free } \\
\text { object } \\
\text { relative }\end{array}$ & $\begin{array}{c}\text { Impersonal pro } \\
\text { object } \\
\text { relative }\end{array}$ \\
\hline Pictures & $92 \%$ & $70 \%$ & $61 \%$ & $85 \%$ & $87 \%$ & $90 \%$ \\
\hline Scenarios & $89 \%$ & $38 \%$ & $50 \%$ & $83 \%$ & $70 \%$ & $75 \%$ \\
\hline Combined & $90 \%$ & $55 \%$ & $56 \%$ & $84 \%$ & $79 \%$ & $83 \%$ \\
\hline No. of participants of 22 who performed above chance & 22 & 7 & 6 & 18 & 17 & 19 \\
\hline Group-level above chance? & Yes & No & No & Yes & Yes & Yes \\
\hline Correlation with age $r=$ & -0.22 & -0.02 & -0.22 & 0.17 & 0.30 & -0.07 \\
\hline$p=$ & 0.33 & 0.94 & 0.33 & 0.46 & 0.18 & 0.74 \\
\hline
\end{tabular}

Whereas each child consistently showed this very clear order of acquisition of various sentence types, chronological age was not a predictor of comprehension in this age range -none of the relative clause types showed a correlation between age and performance, as seen in the last row of Table 4. This finding is consistent with other studies of the acquisition of various types of movement, in which the acquisition was found to be ordered by movement types, but not related to age within the age group in which these structures are acquired (Friedmann and Lavi, 2006).

\subsubsection{Interim discussion 4}

Experiment 4 addressed the complementary case with respect to the structure tested in Experiment 3 . In Experiment 3 we saw that when the target has no lexical NP restriction, no intervention effect is induced by the subject intervener. The current experiment showed that when the subject intervener itself has no lexical NP restriction it does not hamper the dependency even if the target has a lexical NP restriction. The schema in (13) illustrates this case. So the relevant factor seems to be that the target and the intervener cannot both contain a lexical NP restriction.

\section{Impersonal pro object relatives}

D NP R ..... pro arb ....... pronoun ok

The boy who (someone/they) kiss him

A question remains open at this stage: is the lack of intervention effect in this case solely the result of the fact that the subject is pronominal and lacks a lexical NP restriction, or is it also due to its being null? ${ }^{4}$ We leave this question open for further study.

When looking now at the comprehension of the various types of object relatives in experiments $1-4$, significant differences can be noted between the poor performance on headed object relatives, with a gap or with a resumptive pronoun, and the better performance on free object relatives and on object relatives with an impersonal pro subject.

Whereas the group performed at chance on headed object relatives with and without a resumptive pronoun, regardless of the testing method, it performed above chance on free object relatives and on object relatives with an impersonal pro subject. A similar pattern emerges when looking at the number of children who performed above chance on each type of object relatives: Whereas less than a third of the participants performed above chance on headed object relatives and on object relatives with a resumptive pronoun, nearly all of the children performed above chance on free object relatives and on object relatives with an impersonal pro subject.

\footnotetext{
${ }^{4}$ Another independent question is whether the difference in agreement features between the target and the null pronominal subject intervener showing up in the verbal morphology also plays a role. The difference in number can create a featural difference between the target and the intervener which in turn might give rise to a release from RM type effect. Alternatively, one may suggest that children use the inflection on the verb as a morphological clue to determine the elements involved in the wh-dependency. However, recent results with Italian-speaking children, where number agreement does not seem to be an effective feature to resolve ambiguities in object relatives with a post-verbal subject (Arosio et al., 2006), make this alternative less plausible.
} 
Table 5

Comparison of the comprehension of headed object relatives (with two NPs with lexical NP restriction and a trace) to the other types of object relatives

\begin{tabular}{llll}
\hline & Free object relative & Object relative, resumptive pronoun & Object relative, impersonal subject \\
\hline Correct picture & $2.95^{* *}$ & - & $2.95^{* *}$ \\
Correct scenario & $3.21^{* *}$ & $3.12^{* *}$ & $7.07^{* * *}$ \\
Combined & $4.21^{* * *}$ & - & $5.93^{* * *}$ \\
\hline
\end{tabular}

$* * p \leq .01, * * * p<.0005,-:$ not significant.

Table 5 presents the $t$-values for the comparisons between the comprehension of headed object relatives and each of the other types of object relatives. The results indicate that the use of free object relatives and of object relatives with an impersonal pro subject improves the comprehension of object relative clauses across the board, on all comparisons in all of the tasks. The addition of a resumptive pronoun at the original merge position does not improve comprehension (and in the scenario task it even caused poorer comprehension).

The RM-based approach makes a very clear prediction not only with respect to relative clauses, but also with respect to other types of A-bar dependencies, e.g., Wh questions. Specifically, the comprehension of who- and which object questions should differ: whereas in who questions (see examples 14,16), like in free object relatives, the target does not include a lexical NP restriction, and hence no difficulty in comprehension is expected, in which object questions (example 17) the target has a lexical NP restriction. Thus, if the which object question includes a subject with a lexical NP restriction, the subject is expected to give rise to an intervention effect, and make the comprehension of such questions difficult for children. This prediction was tested in Experiment 5.

\section{Experiment 5: The comprehension of which and who questions}

This experiment tested the comprehension of who and which subject and object questions in another group of Hebrew-speaking children.

\subsection{Method}

The participants were 22 children aged 3;7-4;10 (mean age 4;3), 8 girls and 14 boys.

The comprehension of Wh questions was tested using a question-picture matching task. The task included pictures with three figures, two of the same type, and one of a different type. As seen in Fig. 3, the first figure was performing an action on the second, and the second figure was performing the same action on the third one, which was of the same type as the first figure (two dogs, in the case of Fig. 3).

The experimenter asked a question while the participant was looking at a page with the picture. The participant was then requested to point to the figure that matched the question. Each of the participants was tested individually in a quiet room. No time limit was imposed during testing, and no response-contingent feedback was given by the experimenter. The experimenter repeated every item as many times as the participant requested. All the questions were semantically reversible so that comprehension of the meaning of the words alone cannot determine the meaning of the sentence (namely, we did not use irreversible sentences like which boy is eating an apple, only reversible ones like which boy is kissing the grandfather).

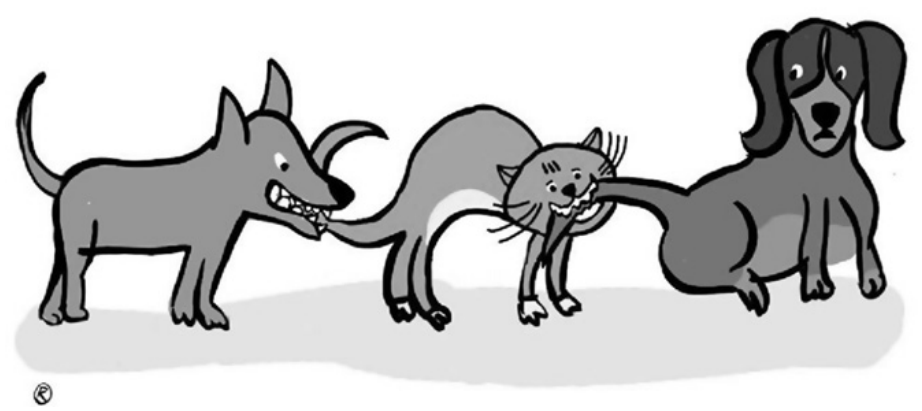

Fig. 3. A picture used in the question comprehension task. 
Prior to the tests, each participant was presented with the pictures and was asked to point to the figures by name ("Show me a cat" and "Show me a dog" for the picture pair in Fig. 3). All participants performed well on this pretest.

A total of 80 Hebrew questions were presented to each participant. These questions included 20 who subject questions, 20 which subject questions, 20 who object questions, and 20 which object questions, see examples (14)-(17) for questions that were presented with Fig. 3. Each of the 20 pictures was presented with all four question types (see Appendix A for a list of the pictures). All verbs were agentive transitives. In each picture all the figures were always of the same gender and number.

$$
\begin{aligned}
& \text { who subject } \\
& \text { Mi noshex et ha-xatul? } \\
& \text { who bites ACC the-cat } \\
& \text { Who bites the cat? }
\end{aligned}
$$

(15) which subject

Eize kelev noshex et ha-xatul?

which dog bites ACC the-cat

Which dog bites the cat?

(16) who object

Et mi ha-xatul noshex?

ACC who the-cat bites

Whom does the cat bite?

(17) which object

Et eize kelev ha-xatul noshex?

ACC which dog the-cat bites

Which dog does the cat bite?

The questions were randomly ordered, and presented in two sessions of 40 sentences each (10 questions of each type per session). The participant saw 20 pictures four times; each picture appeared with all four question types. The correct figure in each pair was randomized both within a session, and between sessions.

\subsection{Results}

The results, presented in Table 6, indicate a clear difference between the good comprehension of all who questions and all subject questions on the one hand, and the poor comprehension of object which questions, on the other.

Whereas subject who and which questions did not differ significantly, $t(21)=1.01, p=.32$, object who questions were significantly better than object which questions, $t(21)=5.48, p<.0001$. Similarly, whereas subject who and object who questions did not differ significantly, $t(21)=1.65, p=.11$, subject which was comprehended significantly better than object which questions, $t(21)=4.69, p<.0001$.

This pattern, of poorer object which questions, can also be seen in the number of children who performed above chance in each question type. Whereas two thirds of the children were above chance with who subject, who object, and which subject questions, only four children performed above chance on the which object questions. The comprehension of all these question types, including object which questions, are mastered by Hebrew-speaking children at the age of 9-10 (Friedmann and Novogrodsky, in press).

Table 6

The comprehension of who and which subject and object questions

\begin{tabular}{lllll}
\hline & Who subject & Which subject & Who object & Which object \\
\hline $3 ; 7-4 ; 5$ & $80 \%$ & $75 \%$ & $72 \%$ & $57 \%$ \\
$4 ; 6-4 ; 10$ & $84 \%$ & $84 \%$ & $81 \%$ & $58 \%$ \\
Total & $81 \%$ & $78 \%$ & $75 \%$ & $58 \%$ \\
No. of participants of 22 who performed above chance & 15 & 14 & 14 & 4 \\
Group-level above chance? & Yes & Yes & Yes & No \\
\hline
\end{tabular}




\subsection{Interim discussion 5}

The results of Experiment 5 confirm the prediction that only if both the target and the intervener have a lexical NP restriction the resulting structure should be difficult for children. This is exactly what we saw in the comparison of headed and free object relatives. This same result was found in the current experiment with respect to Wh questions, schematized in (18). From here on, in order to highlight the similarity or difference of the intervener with respect to the elements involved in the local relation, we adopt the copy theory of traces (Chomsky, 1995), and represent the gap as a silent copy of the antecedent within angled brackets.

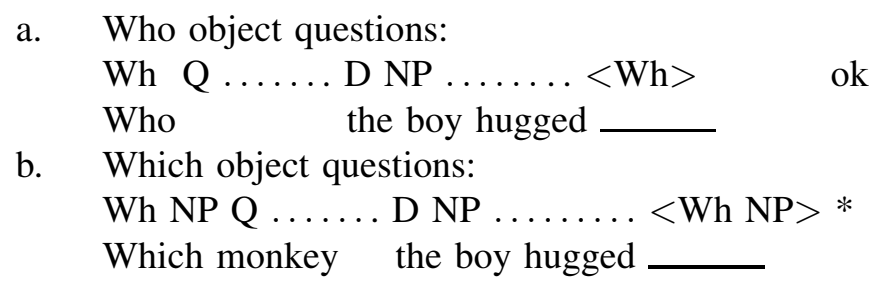

In (18)a the target does not have a lexical NP restriction, and the subject intervener does. In (18)b both the target and the intervener contain a lexical NP.

Similar results, of a difficulty in object which questions, and poorer performance on object-which than object-who questions, were already reported by de Vincenzi (1991) for adults, by de Vincenzi et al. (1999) and Avrutin (2000) for children (see also Hickok and Avrutin, 1996 for similar results on individuals with agrammatic aphasia). Notice, that D-linking cannot be the relevant notion to draw the required distinction between the two cases, because in the given experimental situation both the who and the which object question are D-linked in the same way, as the discourse context is provided by the pictures. (See the general discussion for an argument supporting the view that the presence of a lexical restriction, rather than D-linking, is the relevant factor.)

\section{Experiment 6: Elicited production of relative clauses}

In order to test whether a similar pattern applies for production, we elicited relative clauses with the same children who participated in Experiments 1-4.

\subsection{Method}

Relative clauses were elicited using scenarios, in a similar manner to McKee et al. (1998), based on the methodology suggested by Hamburger and Crain (1982). The participants were invited to play a game with two experimenters. Each of the participants in the game had a particular role. One of the experimenters, appointed the storyteller, used toy animals to stage events according to a fixed script. In each scenario, two identical pairs of animals were displayed, one pair performing the scenario while the other pair was in front of the child but did not do anything. Subsequently, while the animals were still set in the position portrayed by the scenario, the second experimenter covered her eyes, so that she could not see the animals. She was required to take a certain animal that the first experimenter was pointing at. However, as she could not see which object was being pointed at, the child was asked to help her by describing it. In order to describe the specific animal that was being pointed at, the child was required to produce a relative clause (for example: two goats and two gorillas; the scenario: One of the gorillas is patting one of the goats; the target sentence: "Take the gorilla that patted the goat."). The second experimenter kept asking for clarifications regarding the particular animal that she was supposed to take, until the child uttered a description that was sufficient for someone who was unable to see the animals, or until one of the experimenters decided that the child could not produce the full description, and suggested to proceed to the next scenario, to avoid frustration. When the task was completed successfully, the second experimenter took the animal described by the child.

The first scenario presented to the child in the first session was a practice trial. During the practice scenario, the child was given more directions than usual, in the form of guide-questions, and was even presented with the target sentence, if necessary. The game was comprised of seven different scenarios, each including two identical pairs of animals of two different kinds. All the animals participating in a particular scenario were of the same gender. The 
scenarios were the same as the comprehension scenarios (their list is given in Appendix A). Each scenario was demonstrated twice, in two different sessions, once with a particular animal as the agent, and another time with that animal as the theme. For each scenario, the child was requested to produce two target sentences - a subject relative clause and an object relative clause. All in all, each participant was asked to produce 28 sentences, based on 14 scenarios aimed at eliciting subject relatives and 14 scenarios aimed at eliciting object relatives. The verbs chosen for all the scenarios were transitive verbs which require a direct object.

\subsection{Results}

The children showed a preference to produce certain types of relative clauses in a way that matched the gradation of difficulty that was found for the comprehension of relative clauses. The preference to produce subject relatives over object relatives could be seen in two measures - the number of target responses in subject relatives vs. object relatives, and the number of productions of one instead of the other. There were significantly more grammatical productions of subject relatives than of object relatives, $t(21)=3.01, p<.01$, and whereas 54 target object relatives were produced as subject relatives, only one target subject relative was produced as an object relative. Subject relatives were produced in places in which object relatives were targeted by different means: in some cases the verb was replaced (19)a, in other cases the original verb was morphologically changed to a reflexive verb (19)b, and in yet other cases the thematic roles of the arguments were reversed, thus producing an incorrect description of the scene, as exemplified in (19)c.
a. Target:
Ha-jirafa she-ha-zebra nicxa.
the-giraffe that-the-zebra defeated
'The giraffe that the zebra defeated.'
Actual production:
Ha-jirafa she-hifsida.
the-giraffe that-lost
'The-giraffe that lost.'
b. Target:
Ha-pil she-ha-arie hexbi.
the-elephant that-the-lion hid(transitive)
Actual production: Ha-pil she-hitxabe.
the-elephant that-hid(reflexive)
c. Target:
'The elephant that hid (himself).'
Ha-ez she-ha-gorila litfa.
the-goat that-the-gorilla patted
'The goat that the gorilla patted.'
Actual production: Ha-ez she-litfa et ha-gorila. the-goat that-patted ACC the-gorilla
'The goat that patted the gorilla.'

Furthermore, in their production we could see avoidance of object relative structures in which both the target and the embedded subject intervener contain a lexical NP restriction. This was manifested in the use of free object relative clauses and object relative clauses with impersonal pro subject with arbitrary interpretation.
a. Mi she-ha-pil maaxil.
who that-the-elephant feeds
'Who that the elephant is feeding.'
b. Ha-namer she-maaxilim oto.
the-tiger that-feed(pl) him
'The tiger that someone is feeding him.'

Other non-target productions also included a considerable amount of relative clauses with a resumptive pronoun and filled gaps (with full NPs), but the discussion of these facts is beyond the scope of the present discussion. ${ }^{5}$

\footnotetext{
${ }^{5}$ On RM-like intervention effects detected in elicited production see also Franck et al. (2006).
} 


\section{General discussion}

\subsection{The basic pattern}

The main finding presented in this paper is that children aged 3;5-5;0 years deal unproblematically with subjectrelated A' dependencies, whereas object-related A'-dependencies may be selectively problematic, where selectivity is determined by the nature of the A' target and of the subject intervener. The experimental results are summarized by the list in (21).

(21)

\begin{tabular}{|c|c|c|c|c|}
\hline headed subject relative: & D NP1 R & $\ldots \ldots<\mathrm{D} \mathrm{NP} 1>$ & $\ldots \mathrm{D}$ NP2 & ok (example 4) \\
\hline headed object relative: & D NP2 R & $\ldots$. D NP1 & $<\mathrm{D} \mathrm{NP} 2>$ & $* \quad(5)$ \\
\hline III. resumptive object relative: & D NP2 R & $\ldots \ldots$ D NP1 & ... pronoun & $*(8)$ \\
\hline IV. free subject relative: & Wh R & $\ldots<\mathrm{Wh}>$ & D NP & ok (9) \\
\hline free object relative: & Wh R & $\ldots$ D NP & $\ldots<\mathrm{Wh}>$ & ok (10) \\
\hline VI. impersonal pro object relative & D NP R & pro arb & $\ldots$ pronoun & ok (12) \\
\hline VII. subject who question: & Wh Q & $<\mathrm{Wh}>$ & $\ldots$ D NP & ok (14) \\
\hline VIII. object who question: & Wh Q & D NP & $\ldots<\mathrm{Wh}>$ & ok (16) \\
\hline IX. subject which question: & Wh NP2 Q & $<$ Wh NP1 & ... D NP2 & ok $(15)$ \\
\hline object which question: & Wh NP2 Q & D NP1 & $<$ Wh NP2 $>$ & * (17) \\
\hline
\end{tabular}

The gaps in (21)I, II, IV, V, VII, VIII, IX, X are the positions within angled brackets. We have adopted the copy theory of traces, according to which a trace is a silent copy of the moved constituent (Chomsky, 1995). In the cases of the resumptive constructions (21) III and VI we have notated the lower term of the dependency as "pronoun"; under the doubling + stranding derivation of resumptive relatives a gap would be involved in these cases as well.

A' dependencies with subject gaps are generally unproblematic: case I in (21) corresponds to a headed subject relative, clearly accessible to the child, and the same holds for free subject relatives and subject questions (IV, VII, and IX), which are comprehended well by children, whether they are lexically restricted or not. In all these cases, there is no intervener between the target and the trace, as the trace always is in subject position.

Object A' dependencies crucially differ from subject A' dependencies in that they always include an intervener between the target and the trace. Object dependencies may be problematic or not, depending on the internal structure of the moved constituent and of the intervening subject. The generalisation which emerges is that if the A' target and the intervening subject are sufficiently different in internal structure, the configuration is unproblematic, where the critical differential element appears to be the presence or absence of a lexical NP restriction: if the A' target is not lexically restricted, as in free object relatives (V) and who object questions (VIII), an intervening lexically restricted subject does not affect the utilizability of the structure; this also holds when the A' target is lexically restricted but the subject intervener is not, as in the case of headed object relatives across an impersonal pro subject (VI). Whereas, if both the A' target and the subject are lexically restricted, as in headed object relatives (II) and which object questions $(\mathrm{X})$, the structure is problematic. ${ }^{6,7}$

\footnotetext{
${ }^{6}$ Another potential candidate to a subject related intervention effect is the case in which both the relative head and the subject are quantifiers without a lexical restriction. We have not tested this kind of case experimentally, but we observe a reflex of intervention in the slightly marginal status of i.b in Italian, in contrast with i.a and i.c:

i. a Il ragazzo che tutti hanno abbracciato the boy whom all have hugged

b ?Chiunque tutti abbiano abbracciato whoever all have hugged

c Chiunque il ragazzo abbia abbracciato whoever the boy have hugged

${ }^{7}$ Another case in which an object moves across a kind of subject position may be the passive construction, where the object seems to be able to cross over the thematic position of the external argument in its movement to the surface subject position. Presumably, here the intervention is overcome by use of a "smuggling" type derivation (Collins, 2005). The delay of acquisition of passive may then be a consequence of the inherent complexity of this device (for proposals along these lines, see Snyder and Hyams, 2008, on development, and Grillo, 2008, on agrammatism).
} 
Table 7

A summary of problematic and non-problematic dependencies

No intervener - no problem

Target and intervener differ with respect to lexical restriction - no problem

exically restricted target, lexically restricted intervener - problematic
Headed subject relative; which subject question

Free subject relative; who subject question

Free object relative; who object question

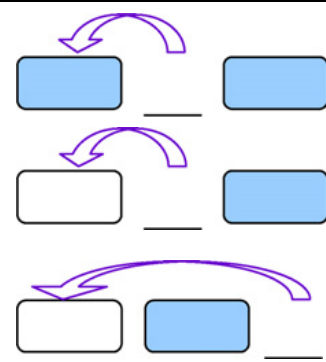

Object relative with arbitrary pro subject

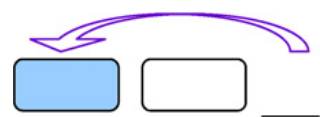

Headed object relative; which object question $=\mathrm{DP}$ with lexical restriction; $\square=\mathrm{DP}$ without lexical restriction.

Thus, as seen in the schematic summary in Table 7, children have difficulties understanding sentences in which there is an intervener between the origin (a trace or a pronoun, marked by an underline) and the target (connected by an arrow to the origin), and both the target and the intervener are lexically restricted (a shaded box). When there is no intervener, or when the intervener and the target do not both carry lexical restriction, children comprehend the sentence.

\subsection{The RM approach}

We have argued that the existence of intervention effects modulated by the similarity of the intervener with the target is clearly reminiscent of the operation of Relativized Minimality, as postulated in the theory of syntactic locality to account for the selective ban on extraction from indirect questions and other weak island contexts (Rizzi, 1990 and much subsequent work). As mentioned before, in the configuration in (7), repeated here as (22), a local relation between $\mathrm{X}$ and $\mathrm{Y}$ fails if the intervener $\mathrm{Z}$ bears a certain structural similarity to $\mathrm{X}$, or, more precisely, $\mathrm{Z}$ belongs to the same structural type as $\mathrm{X}$, where the relevant typology is defined immediately below.

$$
\ldots X \ldots Z \ldots Y \ldots
$$

In this paper we defended the strong position that there is not just a vague family resemblance between the pattern described in (21) and principle (22): our claim is that the very same formal principle is operative in both adult competence and in the developmental effects showed by the experiments reported above. This is in essence the line of analysis which has been assumed in Grillo's (2005, 2008) work on agrammatism. We have explored here a particular implementation of this line of inquiry in connection with development. Let us now try to make the approach more precise.

One critical issue is the formal definition of similarity. RM, as formulated in syntactic theory, does not just pay attention to any sort of similarity between the target and the intervener. In current approaches, the typology of positions formalizing "similarity" is expressed in terms of the featural constitution of X, Z, and Y (see Rizzi, 2004a, for a representational formulation, and Chomsky, 1995, 2000, 2001, for derivational formulations); moreover, only the feature(s) that trigger movement are relevant to define the structural type of a position. So, for instance, in (23) it is the $\mathrm{Q}$ feature triggering movement to the main $\mathrm{C}$ system that gives rise to the effect: the intervener who is also specified with respect to this feature, hence the target-trace connection fails.

$$
\text { * How Q do you wonder who behaved }<\text { how }>\text { ? }
$$

Now, what seems to be critical in configurations II, III, and X of (21) is the presence of a lexical NP restriction both in the target and in the intervening subject; is there any reason to believe that the specification of a lexical NP 
restriction may correspond to a feature capable of triggering movement, hence potentially responsible for a RM effect in the technical sense of current approaches? In fact there are good motivations for that conclusion. It is well-known that not all Wh phrases are equally unextractable from indirect questions and other weak islands.

(24) a ? Which problem do you wonder how to solve?

b * How do you wonder which problem to solve?

Consider familiar contrasts like (24). The lexically restricted Wh phrase which problem is marginally extractable, whereas the bare Wh element how is not. This contrast, originally assumed to illustrate an argument - adjunct asymmetry (Lasnik and Saito, 1984), was later interpreted in terms of the D-linked (discourse-linked) - non-D-linked distinction (Cinque, 1990; Rizzi, 1990); but even that may not be fully satisfactory. Minimal pairs like (25) suggest that the very presence of the lexical restriction in the moved Wh phrase is critical:

(25) a Quanti problemi non sai come risolvere?

'How many problems don't you know how to solve?'

$\mathrm{b} *$ Quanti non sai come risolverne?

'How many don't you know how to solve of-them?'

In (25)a the lexical restriction problemi is pied-piped by the Wh element and the structure is fine; in (25)b the lexical restriction is pronominalized and extracted via ne-cliticization, and the Wh operator is moved alone out of the indirect question, which leads to ill-formedness (even if the D-linked character of the restriction may be the same in both structures). So, the pied-piping of the lexical restriction appears to be crucial to permit extraction from the indirect question (and other weak islands).

In sum, if the lexical restriction is moved with the Wh phrase, extraction from the weak island is possible; if the lexical restriction is removed, extraction from the weak island is strongly precluded. ${ }^{8}$

As in much current work in syntax, we assume that phrasal movement is triggered by a head (the attractor), which attracts a phrase endowed with a matching featural constitution. So, in (23) the attractor is a $Q$ head in the complementizer system, etc. The feature(s) expressed by the attractor and matched by the target are those which may give rise to RM effects (again, the $\mathrm{Q}$ feature in (23)).

Following the spirit of Starke (2001)'s approach, we will assume that lexically restricted Wh phrases are attracted by a complex attractor $[+\mathrm{Q},+\mathrm{NP}]$ (where "NP" designates the lexical restriction, analogous to what Starke calls "range"), whereas bare Wh phrases are attracted by a pure Q attractor (the complex and simple attracting heads presumably occupying distinct positions in the left periphery of the clause, at least in the Northern Italian varieties referred to in footnote 8 ; on the complex cartography of the clausal structure resulting from this approach see the papers collected in the volumes edited by Belletti, 2004; Cinque, 2002; Rizzi, 2004b). Analogously, we may assume that, in a raising analysis, in headed relative clauses the head of the relative will be attracted by a complex attractor $[+\mathrm{R},+\mathrm{NP}]$. We can now integrate the selective problem with headed object relatives of the configuration in (26) observed throughout.

$$
\mathrm{D} N \mathrm{NP}[+\mathrm{R},+\mathrm{NP}] \ldots \ldots \mathrm{D} \mathrm{NP} \ldots \ldots<\mathrm{D} \mathrm{NP}>
$$

The lexically restricted relative position crosses over another lexically restricted position, the subject position. We claim that this configuration violates RM in the child grammar, and this is the basis of the observed difficulties with headed object relatives (and, mutatis mutandis, with lexically restricted object questions, case (21)X).

\subsection{The adult system}

Of course this immediately raises the question of why the adult system can routinely cope with object relatives: configuration (26) is unproblematic for adults. Why is RM not always violated in this configuration? Again,

\footnotetext{
${ }^{8}$ The presence of a lexical restriction appears to affect wh movement in other ways. For instance, Munaro (1999) shows that in certain Northern Italian Dialects lexically restricted and bare wh phrases target distinct positions in the left periphery of the clause.
} 
following Starke, we will assume that RM produces the effect schematically expressed by the contrasting structures in (27).

$$
\begin{array}{llllll}
\text { a. } & +\mathrm{A} & \ldots+\mathrm{A} & \ldots<+\mathrm{A}> & * \\
\text { b. } & +\mathrm{A}+\mathrm{B} & \ldots+\mathrm{A} & \ldots & <+\mathrm{A}+\mathrm{B}> & \text { ok }
\end{array}
$$

In other words, in this system an intervener has the effect of blocking a local A' relation only when it fully matches the featural specification of the attractor, as in configuration (27)a: this happens, e.g., in (23), (24)b, (25)b for A = Q. But the adult grammar has the option of reverting to configuration (27)b: if the attractor is more richly specified in featural terms than the intervener, blocking does not take place, and such cases as (24)a, (25)a are ruled in. These structures instantiate case $(27) \mathrm{b}$, with the lexically restricted operator $(+\mathrm{Q},+\mathrm{NP})$ able to escape from the domain of a bare $(+Q)$ operator.

Clearly, object relatives can be seen as another particular case of (27)b: the lexically restricted head can be attracted to the $\mathrm{R}$ position across the lexically restricted subject position.

$$
[+\mathrm{R},+\mathrm{NP}] \ldots \ldots[+\mathrm{NP}] \ldots .<+\mathrm{R},+\mathrm{NP}>
$$

As seen in (28), the attractor is more richly specified than the intervener, hence the structure is ruled in as an instance of (27)b.

\subsection{Children vs. adults}

What's the source of the discrepancy between children and adults, then? We are led to conclude that children adhere to a somewhat stricter version of RM, requiring not just a distinct featural specification of the target with respect to the intervener, but imposing the stronger requirement of a disjoint specification. ${ }^{9}$ In other words, the adult principle may be satisfied when the target has a featural specification which is globally distinct from the specification of the intervener in that the target's specification properly includes the intervener's specification, in a superset-subset relation, as in (28); whereas the child principle is violated in this case as the stricter disjointness requirement is not met. Disjointness may only be satisfied in a configuration like (27)c, in which the target and the intervener do not share any feature.

$$
\text { c. }+\mathrm{A} \ldots+\mathrm{B} \ldots<+\mathrm{A}>\quad \mathrm{ok}
$$

The proposal is summarized in (29).

$$
\begin{aligned}
& \text { (a) }+\mathrm{A} \ldots \ldots+\mathrm{A} \ldots<+\mathrm{A}> \\
& \text { (b) }+\mathrm{A},+\mathrm{B} \ldots+\mathrm{A} \ldots<+\mathrm{A},+\mathrm{B}> \\
& \text { (c) }+\mathrm{A} \ldots \ldots+\mathrm{B} \ldots<+\mathrm{A}>
\end{aligned}
$$$$
\underset{*}{\text { Adult grammar }} \quad \text { Child grammar }
$$$$
\text { ok }
$$

ok

$*$

(identity)

(inclusion)

(c) $+\mathrm{A} \ldots+\mathrm{B} \ldots<+\mathrm{A}>\quad$ ok

ok

(disjunction)

It may be tempting to speculate that the ban against $(27) \mathrm{b} /(29) \mathrm{b}$ in early systems may relate to a limitation in the operative syntactic memory: clearly, disjointness is easier to determine, as it can be calculated feature by feature, whereas calculating a subset-superset relation requires holding in operative memory and comparing the whole featural specifications associated to different positions, an operation which may exceed the capacity of the early systems (see Grodzinsky and Reinhart, 1993 for similar ideas regarding the difficulties children have in binding structures, and Wexler, 1998, for the idea that certain UG principles may apply in a stricter form in the early systems). The extra

\footnotetext{
${ }^{9}$ An anonymous reviewer observes that, if it is the case that children adhere to a stricter version of Relativized Minimality than do adults, it may be plausible on continuity assumptions to predict that some adult language may similarly be more restrictive. A case in point may be the existence of languages, e.g., Austronesian languages, in which relativization is restricted to the subject position, hence crossing over an intervening subject never arises (Keenan and Comrie, 1977). See Belletti (2008; footnote 17) for relevant discussion.
} 
complexity which configuration (27)b/(29)b involves is consistent with the adult system, which can accept and parse object relatives and similar constructions, but it surfaces in the different form of a delayed and more errorful performance, as evidenced by much adult psycholinguistic work on the parsing of relatives (Cook, 1975; Ford, 1983; Frauenfelder et al., 1980; Hakes et al., 1976). So, the disjointness of features of the target and the intervener seems to be the optimally simple case also in the adult grammar. A partial overlap of features giving rise to a configuration like $(27) /(29) b$ is grammatical, but determines "complexity effects" detectable in experimental work. ${ }^{10}$

Back to the child system: we have seen that a configuration like (26) is disallowed as it violates the "strong" RM requiring featural disjointness. The prediction is that if, in a minimally different construction, we change either the specification of the target, or the specification of the intervener to make them disjoint, we expect that the structures should become possible. This is precisely what we have found in free object relatives and in headed object relatives crossing an impersonal pro subject (see $(21) \mathrm{V}$ and $\mathrm{VI}){ }^{11}$

In free relatives like (21) V, a bare Wh operator is connected to its trace across an ordinary, lexically specified subject: the featural specifications of the target and of the intervener are disjoint, and the connection respects strict RM. Reciprocally, in a headed relative like (13) the intervening subject is an impersonal null pronoun; whatever the exact details of the construction may be, the impersonal pro subject clearly is not lexically restricted, hence the requirement of featural disjointness of strict RM is satisfied, and the lexical head can be related to its trace across the intervening subject. Similar conclusions hold in the case of questions, as seen in ((21)VIII vs. X).

In questions involving a bare Wh operator like ((21)VIII) the disjointness requirement is clearly satisfied, so that no intervention effect is observed. On the other hand, in questions with lexically restricted Wh operators like ((21)X), the intervening subject shares part of the specification of the operator, i.e., the lexical restriction, so that disjointness is not met, strict RM applies to block the relation connecting the target and its trace, and the child cannot cope with an object question with a lexically restricted operator.

In conclusion, the acquisition of A' constructions follows a complex pattern, with selective delays of object A' dependencies in certain structural contexts but not in others. The double goal of this paper has been to uncover this complex pattern by conducting a series of experiments in comprehension and also in production; and to provide a structural analysis of the pattern based on current models of syntactic locality. We have claimed that the observed selective intervention effects bear more than a vague resemblance to Relativized Minimality effects advocated by syntacticians: the very formal principle which is deemed responsible for selective extractability from weak islands in adult grammars can enter, through natural auxiliary hypotheses, into a structural explanation of the selective difficulties with object $A^{\prime}$ dependencies observed in children.

\section{Acknowledgments}

We thank Noa Günzberg-Kerbel and Lilach Shvimer for their help in administering the tests. This research was supported by the Lieselotte Adler Laboratory for Research in Child Development, and the writing of this manuscript was supported by the COST A33 European initiative.

\footnotetext{
${ }^{10}$ Notice that the successful extractions from weak islands such as (24)a, (25)a are often perceived as marginal by adults, whereas object relatives, also instantiating configuration (27)b/(29)b in our analysis, are not. The different acceptability status between the two cases is presumably due to the compounded effect of a subjacency-type violation, which is also involved in the extraction from weak islands, but not in object relatives.

${ }^{11}$ The case of the unproblematic comprehension of both free object relatives and object relatives with a impersonal null subject pronoun clearly indicates that the difficulty with object relatives is not solely overcome by changing the nature of the intervener (e.g., by making it less referentially heavy/new than the target through the use of a pronoun, as has been proposed, most notably by Warren and Gibson, 2002, 2005, in the context of nested dependencies). Changing the nature of the target, e.g., by eliminating its lexical restriction while leaving the intervener fully lexically restricted as in the free object relative case, has the same facilitating effect. This result is predicted by the RM approach adopted here, but it is not predicted by any account exclusively focussing on the nature of the intervening subject (be it structural, or concentrated on the discourse value of the intervening subject, as in the recent discussion in Mak et al., 2008). Note finally that the structural distance of the dependency does not seem to play a role in accounting for the difficulty with object relatives, as the target and the origin are equally distant from each other in all kinds of object relatives considered here.
} 


\section{Appendix A. Description of the pictures used in the experiments}

a. Experiments 1-4: Relative clause comprehension, 28 pictures

Girl kissing grandma

Boy wetting father

Dog biting cat

King pinching doctor

Girl drying woman

Grandma swinging girl

Girl putting-make-up-on woman (putting make-up has a verb in Hebrew)

Boy kissing grandpa

Boy drying hippo

Girl drawing woman

Horse combing boy

Giraffe washing girl

Dog swinging boy

Soldier drawing doctor

Rabbit pushing penguin

Elephant wetting lion

Girl photographing woman

King combing boy

Boy washing penguin

Monkey hugging boy

Cow licking giraffe

Boy pulling old man

Prince covering dwarf

Girl combing hen

Girl feeding grandma

Queen hugging girl

Elephant drawing boy

Dwarf photographing prince

b. Experiments 1-4: acted-out scenarios

The seven acted-out scenes for the comprehension of relative clauses were presented twice each, once with one NP as agent and another time with the other NP as agent. These 14 scenarios were acted out six times, for each relative clause type.

Horse makes a hippo fall (make-fall is a verb in Hebrew)

Zebra passing giraffe

Bear pushing duck

Cow kissing hen

Lion hiding elephant

Goat petting gorilla

Tiger feeding the rhino

c.. Pictures used in the Wh question comprehension test

Angel petting boy who pets another angel

Fish catches diver who is catching another fish

Boy feeding clown who is feeding another boy 
Girl photographing nurse who is photographing another girl

Boy pushes father who pushes another boy

Grandma in wheelchair pinching girl who pinches a standing grandma

Big bear driving boy in wheelchair who pushes a teddy-bear in stroller

Princess catching dancer who is catching another princess

Father wetting (spilling a bucket of water on) a boy who is wetting another father

Fireman cleaning boy who is cleaning another fireman

Princess combing a girl combing a little princess

Boy wetting (with a hose) father who is wetting another boy

Tall giraffe measuring a girl who is measuring a small giraffe

Girl petting mother who is petting another girl

Girl cutting-hair of a woman who is cutting-hair for another girl (cutting hair is a verb in Hebrew)

Soldier holding a hippo who is holding another soldier

Man pulling a boy sitting a wagon, who is pulling another man on a wagon

Dog biting cat who is biting another dog

Dolphin drying boy who is drying another dolphin

Elephant wetting a boy who is wetting another elephant

\section{References}

Abney, S.P., 1987. The English noun phrase in its sentential aspect. Doctoral dissertation, MIT Press, Cambridge, MA.

Adams, C., 1990. Syntactic comprehension in children with expressive language impairment. British Journal of Disorders of Communication 25, 149-171.

Arosio, F., Adani, F., Guasti, M.T., 2006. Processing grammatical features by Italian children. In: Supplement 30th Proceeding of Boston University Conference on Language Development.

Avrutin, S., 2000. Comprehension of Wh-questions by children and Broca's aphasics. In: Grodzinsky, Y., Shapiro, L.P., Swinney, D.A. (Eds.), Language and the Brain: Representation and Processing. Academic Press, San Diego, pp. 295-312.

Belletti, A. (Ed.), 2004. Structures and Beyond: The Cartography of Syntactic Structure, vol. 3. Oxford University Press, New York.

Belletti, A., 2005. Extended doubling and the vP periphery. Probus 17, 1-35.

Belletti, A., 2006. Extending doubling to non local domains: complete vs. partial copying + deletion and related reconstruction issues. In: Brandt, P., Fuss, E. (Eds.), Form, Structure and Grammar. Akademie Verlag, Berlin, pp. 129-136.

Belletti, A., 2008. Notes on passive object relatives. In: Svenonius P. (Ed.), Functional Structure from Top to Toe.

Berman, R., 1997. Early acquisition of syntax and discourse in Hebrew. In: Shimron, Y. (Ed.), Psycholinguistic Studies in Israel: Language Acquisition, Reading and Writing. Magnes Press, Jerusalem, (in Hebrew), pp. 57-100.

Bianchi, V., 1999. Consequences of Antisymmetry: Headed Relative Clauses. Mouton De Gruyter, Berlin.

Boeckx, C., 2003. Islands and Chains: Resumption as Stranding. John Benjamins, Amsterdam.

Brown, H., 1972. Children's comprehension of relativized English sentences. Child Development 42, 1923-1936.

Chomsky, N., 1995. The Minimalist Program. MIT Press, Cambridge, MA.

Chomsky, N., 2000. Minimalist inquiries: the framework. In: Martin, R., Michaels, D., Uriagereka, J. (Eds.), Step by Step - Essays in Minimalist Syntax in Honor of Howard Lasnik. MIT Press, Cambridge, MA.

Chomsky, N., 2001. Derivation by phase. In: Kenstowicz, M. (Ed.), Ken Hale: A Life in Language. MIT Press, Cambridge, MA.

Cinque, G., 1990. Types of A'-dependencies. MIT Press, Cambridge.

Cinque, G. (Ed.), 2002. Mapping Functional Structure: The Cartography of Syntactic Structures, vol. 1. Oxford University Press, Oxford and New York.

Collins, C., 2005. A smuggling approach to the passive in English. Syntax 8, 81-120.

Cook, V.J., 1975. Strategies in the comprehension of relative clauses. Language and Speech 18, 204-212.

Correa, L.M., 1982. Strategies in the acquisition of relative clauses. In: Aitchison, J., Harvey, N. (Eds.), Working Papers of the London Psycholinguistic Research Group, vol. 4. pp. 37-49.

Correa, L.M.S., 1995. An alternative assessment of children's comprehension of relative clauses. Journal of Psycholinguistic Research $24,183-203$.

Crain, S., Fodor, J.D., 1985. How can grammars help parsers? In: Dowty, D., Karttunen, L., Zwicky, A. (Eds.), Natural Language Parsing: Psychological, Computational, and Theoretical Perspectives. Cambridge University Press, Cambridge, UK, pp. 94-128.

de Villiers, J.G., de Villiers, P.A., Hoban, E., 1994. The central problem of functional categories in the English syntax of oral deaf children. In: TagerFlusberg, H. (Ed.), Constraints on Language Acquisition: Studies of Atypical Children. Erlbaum, Hillsdale, NJ, pp. 9-47.

de Vincenzi, M., 1991. Syntactic Parsing Strategies in Italian: The Minimal Chain Principle. Kluwer, Dordrecht, The Netherlands.

de Vincenzi, M., Arduino, L.S., Ciccarelli, L., Job, R., 1999. Parsing strategies in children comprehension of interrogative sentences. In: Bagnara, S. (Ed.), Proceedings of European Conference on Cognitive Science. Istituto di Psicologia del CNR, Rome, pp. 301-308. 
Ford, M., 1983. A method for obtaining measures of local parsing complexity throughout sentences. Journal of Verbal Learning and Verbal Behavior 22, 203-218.

Franck, J., Lassi, G., Frauenfelder, U., Rizzi, L., 2006. Agreement and movement: a syntactic analysis of attraction. Cognition 101, 173-216. Frauenfelder, U., Segui, J., Mehler, J., 1980. Monitoring around the relative clause. Journal of Verbal Learning and Verbal Behavior 19, $328-337$. Frazier, L., Clifton Jr., C., 1989. Successive cyclicity in the grammar and the parser. Language and Cognitive Processes 4, 93-126.

Frazier, L., Flores d'Arcais, G., 1989. Filler-driven parsing: a study of gap-filling in Dutch. Journal of Memory and Language 28, 331-344.

Frazier, L., Clifton Jr., C., Randall, J., 1983. Filling gaps: decision principles and structure in sentence comprehension. Cognition 13, 187-222. Friedmann, N., 2008. Traceless relatives: a grammatic comprehension of relative clauses with resumptive pronouns. Journal of Neurolinguistics 21 , $138-149$.

Friedmann, N., Lavi, H., 2006. On the order of acquisition of A-movement, Wh-movement and V-C movement. In: Belletti, A., Bennati, E., Chesi, C., Di Domenico, E., Ferrari, I. (Eds.), Language Acquisition and Development. Cambridge Scholars Press/CSP, Cambridge, UK, pp. $211-217$.

Friedmann, N., Novogrodsky, R., 2002. BAMBI: Battery for assessment of syntactic abilities in children. Tel Aviv University (in Hebrew).

Friedmann, N., Novogrodsky, R., 2004. The acquisition of relative clause comprehension in Hebrew: a study of SLI and normal development. Journal of Child Language 31, 661-681.

Friedmann, N., Novogrodsky, R., Which questions are most difficult to understand? The comprehension of Wh questions in three subtypes of SLI. Lingua, in press.

Friedmann, N., Shapiro, L.P., 2003. Agrammatic comprehension of simple active sentences with moved constituents: Hebrew OSV and OVS structures. Journal of Speech Language and Hearing Research 46, 288-297.

Grillo, N., 2005. Minimality effects in agrammatic comprehension. In: Blaho, S., Schoorlemmer, E., Vicente, L. (Eds.), Proceedings of ConSOLE XIII. pp. 106-120, Available at http://www.sole.leidenuniv.nl/.

Grillo, N., 2008. Generalized minimality: syntactic underspecification in Broca's aphasia. Doctoral dissertation distributed by LOT, University of Utrecht, The Netherlands.

Grodzinsky, Y., 2006. A blueprint for a brain map of syntax. In: Grodzinsky, Y., Amunts, K. (Eds.), Broca's Region. Oxford University Press, New York.

Grodzinsky, Y., Reinhart, T., 1993. The innateness of binding and of coreference. Linguistic Inquiry 24, 69-101.

Grosu, A., 2003. A unified theory of 'standard' and 'transparent' free relatives. Natural Language and Linguistic Theory 21, $247-331$.

Günzberg-Kerbel, N., Shvimer, L., Friedmann, N., 2008. "Take the Hen that the cow kissed the hen": the acquisition of comprehension and production of various relative clauses in Hebrew. Language and Brain 7, $23-43$ (in Hebrew).

Håkansson, G., Hansson, K., 2000. Comprehension and production of relative clauses: a comparison between Swedish impaired and unimpaired children. Journal of Child Language 27, 313-333.

Hakes, B., Evans, J., Brannon, L., 1976. Understanding sentences with relative clauses. Memory and Cognition 4, $283-296$.

Hamburger, H., Crain, S., 1982. Relative acquisition. In: Kuczaj, II, S. (Ed.), Language Development: Syntax and Semantics. Erlbaum, Hillsdale, NJ.

Hickok, G., Avrutin, S., 1996. Comprehension of Wh-questions in two Broca's Aphasics. Brain and Language 52, 314-327.

Kayne, R., 1994. The Antisymmetry of Syntax. MIT Press, Cambridge, MA.

Keenan, E.L., Comrie, B., 1977. Noun phrase accessibility and universal grammar. Linguistic Inquiry 8, 63-99.

Lasnik, H., Saito, M., 1984. On the nature of proper government. Linguistic Inquiry 15, 235-289.

Mak, W.M., Vonk, W., Schriefers, H., 2008. Discourse structure and relative clause processing. Memory and Cognition 36, $170-181$.

McKee, C., McDaniel, D., Snedeker, J., 1998. Relative children say. Journal of Psycholinguistic Research 27, 573-596.

Munaro, N., 1999. Sintagmi interrogativi nei dialetti italiani settentrionali. Unipress, Padua, Italy.

Rizzi, L., 1990. Relativized Minimality. MIT Press, Cambridge, MA.

Rizzi, L., 2004a. Locality and left periphery. In: Belletti, A. (Ed.), Structures and Beyond: The Cartography of Syntactic Structures, vol. 3. Oxford University Press, Oxford-New York.

Rizzi, L. (Ed.), 2004. The Structure of CP and IP: The Cartography of Syntactic Structures, vol. 2. Oxford University Press, New York.

Roth, P.F., 1984. Accelerating language learning in young children. Journal of Child Language 11, 89-107.

Sheldon, A., 1974. The role of parallel function in the acquisition of relative clauses in English. Journal of Verbal Learning and Verbal Behavior 13, $272-281$.

Shlonsky, U., 1997. Clause Structure and Word Order in Hebrew and Arabic. Oxford Press, New York.

Snyder, W., Hyams, N., 2008. Young children are frozen: reflexive clitics and the universal freezing hypothesis. Unpublished manuscript.

Starke, M., 2001. Move dissolves into Merge: a theory of locality. Unpublished doctoral dissertation, University of Geneva, Geneva, Switzerland.

Stowe, L.A., 1986. Parsing Wh-constructions: evidence for on-line gap location. Language and Cognitive Processes 1, $227-245$.

Tavakolian, S.L., 1981. The conjoined-clause analysis of relative clauses. In: Tavakolian, S.L. (Ed.), Language Acquisition and Linguistic Theory. MIT Press, Cambridge, MA, pp. 167-187.

Vergnaud, J.-R., 1974. French relative clauses. Unpublished doctoral dissertation, MIT, Cambridge, Mass.

Warren, T., Gibson, E., 2002. The influence of referential processing on sentence complexity. Cognition 85, 79-112.

Warren, T., Gibson, E., 2005. Effects of NP type in reading cleft sentences in English. Language and Cognitive Processes 20, 751-767.

Wexler, K., 1998. Very early parameter setting and the Unique Checking Constraint: a new explanation of the Optional Infinitive stage. Lingua 106, $23-79$. 